\title{
A clinician's view of public health care in Quebec
}

\author{
Interview with Dr. Paul Saba, Family Physician \\ Interviewed by Samuel Lapalme-Remis for the MJM
}

MJM: Please describe how your divide you practice on a week-to-week basis.

Dr. Saba: I work about one week a month doing hospitalization at the Lachine Hospital in Montreal. I do another week of mixed hospitalization, either with intensive care or without intensive care. I do about two weeks a month altogether in practice at my clinic; I try to be in my office at least three weeks out of four, two to three days a week. I also work at the emergency room whenever they need me; I probably put in about six shifts a month. So I do a pretty wide spectrum of medical practice, which I find very interesting.

MJM: What led you to pursue this kind of career?

Dr. Saba: I had always worked a little bit in everything; at one point my practice leaned more toward office practice but then around 2000, when there was a big cry for doctors in emergency rooms, I answered the call and started working in rural areas part-time. I believe in the public system and I thought that if we're going to make the public system work, we have to participate in helping where the need is. Then about four years ago, my colleagues asked me to come to Lachine Hospital because there was a shortage of doctors. Then there was a push to downsize the hospital and turn it into a clinic, so I became president of the local chapter of physicians and took on a leadership role to fight to maintain it as a community hospital. That's what I've been doing recently.

In the past, after graduating from the Faculty of Medicine at McGill University in 1980, like a lot of my colleagues, I left Quebec. I did my residency in internal medicine in the United States and stayed on to work

*To whom correspondence should be addressed:

Paul Saba

Lachine Hospital

650 16e Ave

Lachine, Quebec

H8S 3N5

paul.saba@sympatico.ca there for several years. Then from 1994 to 1996, I participated in a Canadian project in the Ivory Coast, I was the director of a community health project there. Working there, I realized that I really appreciated what Canada had. I decided in 1996 that I wanted to come back to Quebec and I've been here ever since.

MJM: What originally prompted you to leave Quebec?

Dr. Saba: Part of it was that when I first left Quebec, I felt that as an Anglophone I didn't really have a part in the society here. There was always political unrest; you never knew if Quebec would separate or not. I felt that there wasn't any future for anglophone doctors practicing in Quebec in the long run. I've since changed my mind on that.

MJM: What made you change your opinion?

Dr. Saba: I think that we have a wonderful model of health care, despite the waiting times and cutbacks. Secondly, as anglophones, we can master French adequately to practice and be comfortable, and to help in the development of Quebec. Whatever Quebec's political future, as physicians our focus should be on providing health care. If anything, we can help build bridges. Here I've been very involved, as an anglophone, to defend the only francophone hospital in the West Island of Montreal [Lachine Hospital]. I play the same role as co-president of the Coalition of Physicians for Social Justice in defending publiclyfunded health care in Quebec. I think it shows that we as anglophones can play an essential role in defending social justice and health care needs of the poor in Quebec, whether they're anglophone or francophone.

By remaining here, it shows that we're not here just for our own financial interest, because we do have opportunities as anglophones to practice elsewhere. By making a decision to stay here, I think it shows that we care. We have a great opportunity here to heal physically, spiritually and even politically. As physicians we should see ourselves as healers of people 
and not of one or another political party. We are ambassadors for health.

МJM: Does assuming such a role require personal sacrifice?

Dr. Saba: If I didn't get involved in fighting for things that I believe in, whether that be saving a hospital or saving public health care...there is a cost. There's a cost in term of time. I'm often torn because of my family responsibilities, leaving my young children, sometimes to have to go to a meeting or do an interview. But in the long term it's less frustrating, I sleep better at night and I'm not as angry.

I see some of my colleagues sometimes who feel very flustered and frustrated, who feel like victims of a system that's gone awry. So I tell them, "get involved, spend some time to promote and defend our health care system, try to improve it. If you believe that public health care is the way to go, do everything you can to ensure that it works to its maximum."

MJM: Why are you committed to working within and promoting the public health care system?

Dr. Saba: I prefer to live in a system that is striving for more equity, ensuring a fair health care system for all, including our neighbours, friends, people we don't know, or relatives who are less well-off financially. There are lots of studies that show that public health care offers better medical care. Publicly funded health care offers better outcomes at a better cost than private health care. Given the evidence, we can't help but support a system that has worked well in the past.

MJM: What makes government the most appropriate provider of health care?

Dr. Saba: It's not so much government but a government-based insurance. When patients receive care not based on their own pocketbook, studies have shown that patients get more timely access to care and they also get guaranteed access. There are delays but the people who are most acutely ill get the care they need. Where money becomes a factor, people delay getting care or they don't get it at all.

However, the government needs to offer adequate salaries to health care providers and ensure that doctors working in offices can cover their expenses. This is necessary to provide the quality of care that people need and also to keep health care workers in the province. In Quebec, our per-capita health care expenditure is often the lowest in Canada. You can't get by on the cheap. So that's a proviso.

MJM: In your opinion, is that what the government is trying to do?

Dr. Saba: Yes. And that's unacceptable. And it's created this situation where medical graduates, on whom we spend lots of money to train, are leaving the province. We need to do everything we can to make it attractive for graduates to stay. It's not just a question of increasing enrolments, but also making sure they have a position once they graduate and that they can practice where they want to. If you really want them to go to rural areas, you can't do it by coercion.

MJM: What are some of the frustrations involved with dealing with the present system?

Dr. Saba: I think that we are overstaffed with administrators. I'm not talking about the ward clerk who works very hard on the floors or the support staff in the hospitals. I'm talking about the administrative assistants to the directors, the people at higher levels. Each health care institution has its own character and the administrators don't always respect or understand that. The money that goes to funding these extra layers of bureaucracy would be better spent on health care workers.

MJM: Why wouldn't introducing private health care put pressure on these institutions to be more efficient?

Dr. Saba: Where competitive models have been introduced, like in Australia or New Zealand, there was either a slight improvement or no improvement in efficiency, and eventually it winds up costing more. It would be a dangerous path to follow to jump into a system where the evidence shows no benefit.

MJM: Clearly there are major problems with the system as it is. How can improvements be made?

Dr. Saba: For waiting times, for example, with cardiac surgery in Ontario they have a coordinator that looks at waiting times from hospital to hospital and gets people who need surgery from one place to another. Just listing the waiting times at different hospitals on the internet and expecting the person with chest pains to make the call is not a solution. That's unquestionable. We need to coordinate that to direct people to hospitals where there are shorter waiting times. We don't need to offload patients to private clinics; within our own hospitals we can provide care.

Where there are excessive waiting times everywhere, we need to increase the efficiency of our operating rooms. Right now we have zero-deficit so each hospital is allocated a certain amount of money. If they go above that amount, they're penalized. There's got to be more flexibility in the budget. If a hospital gets more cases than it expects, it should get the budget it needs to deal with them. You can pay extra hours to staff; everyone needs a bit of extra money. You can do all this within the system, you don't need all these extra private clinics.

MJM: But you do need to spend more money.

Dr. Saba: You need the budget to provide the care. Right now there's no margin. Budgets are planned a year ahead and administrators get bonuses if they can stay within budget or go below budget. So administrators are paid to decrease the amount of care 
that goes to patients. It shouldn't be like that.

MJM: What advice would you give a young person beginning a career in medicine as a physician?

Dr. Saba: Go into the field of medicine that you most want to do. Don't let the money put you into an area that you don't want, otherwise you'll be very frustrated and very unhappy. Choose the path that's most fulfilling. Whether you go into the private or the public sector, follow your convictions.

It's a sacrifice, whatever field of medicine you go into. Don't allow the frustrations, the bureaucrats, the bureaucracy, the government, to take away your joy of medicine. If you feel something's wrong, fight to make it right.

Paul Saba, MD, is a graduate of the McGill University Faculty of Medicine. He is currently on active staff at the Lachine Hospital and in practice at Médi-Centre de Montréal-Ouest in family medicine. He is Co-President of the Coalition of Physicians for Social Justice, which advocates for publicly-funded health care. 